\title{
1 Numerical Modeling of a Church Nave Wall Subjected 2 to Differential Settlements: Soil-Structure Interaction, 3 Time-Dependence and Sensitivity Analysis
}

\section{$4 \quad$ Anastasios Drougkas ${ }^{1}$}

5 Building Materials and Building Technology Division, Civil Engineering Department, KU Leuven,

6 Kasteelpark Arenberg 40 Box 2448, B-3001 Heverlee, Belgium

Els Verstrynge

Building Materials and Building Technology Division, Civil Engineering Department, KU Leuven,

9 Kasteelpark Arenberg 40 Box 2448, B-3001 Heverlee, Belgium

\section{Pepijn Szekér}

11 Building Materials and Building Technology Division, Civil Engineering Department, KU Leuven,

12 Kasteelpark Arenberg 40 Box 2448, B-3001 Heverlee, Belgium

\section{Gert Heirman}

Triconsult nv, Lindekensveld 5 box 3.2, B-3560 Lummen, Belgium

\section{Leidy-Elvira Bejarano-Urrego}

Building Materials and Building Technology Division, Civil Engineering Department, KU Leuven,

17 Kasteelpark Arenberg 40 Box 2448, B-3001 Heverlee, Belgium

\footnotetext{
${ }^{1}$ Corresponding author, email: anastasios.drougkas@kuleuven.be
} 
Giorgia Giardina

Department of Architecture and Civil Engineering, University of Bath, Claverton Down, Bath, BA2 7AY,

United Kingdom

\section{Koenraad Van Balen}

Building Materials and Building Technology Division, Civil Engineering Department, KU Leuven, Kasteelpark Arenberg 40 Box 2448, B-3001 Heverlee, Belgium

\section{Abstract}

caused by deformable soil, shallow or inadequate foundation, structural additions in the building and changes in the underground water table due to the large-scale land use change in urban areas.

This paper deals with the numerical modeling of a church nave wall subjected to differential settlement caused

by a combination of the above factors. The building in question, the church of Saint Jacob in Leuven, has suffered extensive damage caused by centuries-long settlement. A numerical simulation campaign is carried out in order to reproduce and interpret the cracking damage observed in the building.

The numerical analyses are based on material and soil property determination, the monitoring of settlement in the church over an extended period of time and soil-structure interaction. A sensitivity study is carried out, focused on the effect of material parameters on the response in terms of settlement magnitude and crack width and extent.

Soil consolidation over time is considered through an analytical approach. The numerical results are compared with the in-situ observed pathology and with an analytical damage prediction model.

\section{Keywords}




\section{$39 \quad$ Highlights}

\section{Notation}

47

48

49

50

51

52

53

54

55

56

57

58
- A masonry church nave wall subjected to differential settlements is numerically modeled, considering time-dependent material properties and changes in geometry and loading

- The foundation and the soil properties are considered

- A sensitivity analysis highlights the parameters affecting the cracking pattern and extent

- The phased analysis results in a much more accurate representation of the observed damage compared to a single-phase model

Young's modulus

shear modulus

Poisson's ratio

mass density

tensile stress

crack strain

ultimate strain

compressive strength

tensile strength

tensile fracture energy

characteristic finite element length

footing half-length 


$$
D^{j} \quad \text { footing embedment depth }
$$

61

$$
A_{f}^{j} \quad \text { footing area }
$$

62

$$
A_{w}^{j} \quad \text { footing side-wall contact area }
$$

$$
K_{n}^{j} \quad \text { footing vertical elastic stiffness }
$$

$64 \quad k_{n}^{j} \quad$ footing modulus of subgrade reaction

$$
k_{n} \quad \text { wall/colonnade modulus of subgrade reaction }
$$

\section{1. Introduction}

\section{$67 \quad$ 1.1 State of the Art}

The analysis of large monumental structures subjected to differential ground movement is a challenging subject of study. The challenge mainly arises from geometric complexity and sheer size, problems only partially alleviated by a detailed geometric survey, material property determination and the definition of the applied deformation load profile through concerted monitoring efforts [1]. It is, however, a worthwhile endeavor in service of estimating the risk of damage or collapse and designing effective intervention strategies for repair and strengthening.

The discretization of monumental church structures in macro-elements with different stiffness is often considered conceptually and empirically valid. Macro-elements, such as façades, towers, apses and single naves, are often separated through insufficient tying and the presence of structural cracking. They are further characterized by different stiffness, weight and internal stresses. Namely, the effects of earthquake action and differential settlement loading affect different parts of the structure in distinct ways. Therefore, the problem of structural analysis of large churches can be simplified by pursuing it on an individual macro-element basis [2]. It 
is both practical and valid to study certain components of monumental church structures, such as single bays, naves, façades or towers individually.

In a nonlinear finite element (FE) analysis framework, the large dimensions of monumental church structures built in masonry can render detailed modeling computationally prohibitive and model preparation effort excessive. Macro-modeling, therefore, which consists in the homogenous modeling of the masonry composite, becomes a suitable alternative. Despite the assumption of homogeneity, nonlinear macro-modeling of large masonry structures can provide insight into the mechanisms through which damage arises and expands $[3,4]$.

Predictive models for damage estimation and categorization in masonry structures subjected to differential ground movement have been proposed in the literature [5]. These models rely on the determination of parameters related to the material, geometric and foundation properties of the structure and are mostly used to evaluate the effects of tunneling-induced settlements. The analytical and parametric basis of these models allows their adoption and modification according to the requirements of a variety of loading scenarios and foundation types. This basis further allows the parallel application with, and direct comparison to, numerical modeling of damage induced by differential ground settlement.

In this paper both numerical and analytical models are applied for the analysis of a large monumental structure. The church of Saint Jacob in Leuven has been the subject of wide and inclusive study over the preceding decades [6-8]. It is characterized by extensive and developing pathology due to differential ground movement. This pathology is well documented and extensive data is available on the profile of ground movement over different periods. Finally, studies have been performed on its material properties, the stress state of its structural elements and the properties of the foundation soil. It is therefore a prime candidate for investigation through analytical 100 simulation and numerical analysis for the purpose of interpreting the damages present in the fabric and the development of ground movement. 


\subsection{Objectives}

103 The focus of the present paper is the numerical reproduction of the damage patterns observed through time in

104 the church of Saint Jacob in Leuven, the investigation of their underlying cause, namely the differential settlements

105 at the site, and the study of the effect of material and numerical analysis parameters in the obtained results. This

106 is accomplished through a sensitivity study involving the material properties of the masonry structure, the

107 application of different loading patterns in the form of settlement profiles and the variation of the boundary

108 conditions as affected by the passage of time.

109 The interpretation of the results of the numerical analyses, coupled with the assembly and evaluation of historic

110 data, on-site observations and structural monitoring aim at providing insight into the manifestation and

111 development of structural pathology in the monument. A quantitative assessment of the development in time of

112 soil consolidation under the effect of gravity loads is given, thus outlining the behavior of the monument over an 113 extended period.

114 Further interpretation and quantification of the numerical results is provided through their comparison with 115 simplified analytical damage assessment models. This comparison allows the evaluation of the applicability of 116 analytical models in monumental masonry structures and demonstrates their potential for the interpretation of 117 current and the prediction of future structural damage.

\section{2. The Case Study}

\section{$119 \quad 2.1$ Layout and Brief Historic Outline}

120 Details on the history of the construction of the church may be found in [6], with the main points repeated here

121 for clarity. Construction of St. Jacob's church began around 1220, with the erection of the tower over the remnants 122 of an existing Romanesque church. The initial plan called for the church to have a flat timber ceiling, which was 123 later substituted for a timber barrel vault. The main nave, at its originally intended height, was completed in the $12414^{\text {th }}$ century, along with the side naves and their stone vaults, and the bell tower over the crossing was added in 125 the $15^{\text {th }}$. During the period $1534-1535$, an additional level over the main nave was added and masonry vaults were 
added in place of the timber vault, which was complemented by the addition of two, possibly four, pairs of flying

buttresses. These alterations resulted in the addition of self-weight not originally anticipated in the construction of the foundations.

First mention of structural problems stemming from differential settlement dates back to at least the $15^{\text {th }}$ century. These problems led to the reconstruction of the side nave vaults. The timber bell tower over the crossing was dismantled in 1735 due to concerns over its decay. The development of vertical cracking in the pillars led to the installment of confining steel rings in the early $19^{\text {th }}$ century, still present. Further consolidation measures were taken in the early $20^{\text {th }}$ century due to severe cracking in the west wall of the northern transept. In 1963 , the entire church was definitively closed for the public. During the partially executed consolidation works of 1965-1971, the structure was internally shored using massive reinforced concrete elements and steel profile braces. While only foreseen as a temporary measure, the shoring members are still present today. Additionally, the side nave vaults were dismantled for weight reduction. In 2000 the flying buttresses were removed due to their being severely outof-plumb, which raised concerns of sudden collapse, and were replaced by temporary steel tie-rods. A comprehensive structural intervention project, including localized repairs on the masonry a micro-piling reinforcement of the foundations and reconstruction of the dismantled elements (side nave vaults and flying buttresses) and soil consolidation was launched in September 2018 [9].

A floor plan of the church, along with the designation of the construction phases, can be seen in Figure 1 . The construction process, beginning with the tower and following with the arcade, naves, transept, chapels and finally the choir are indicated. 


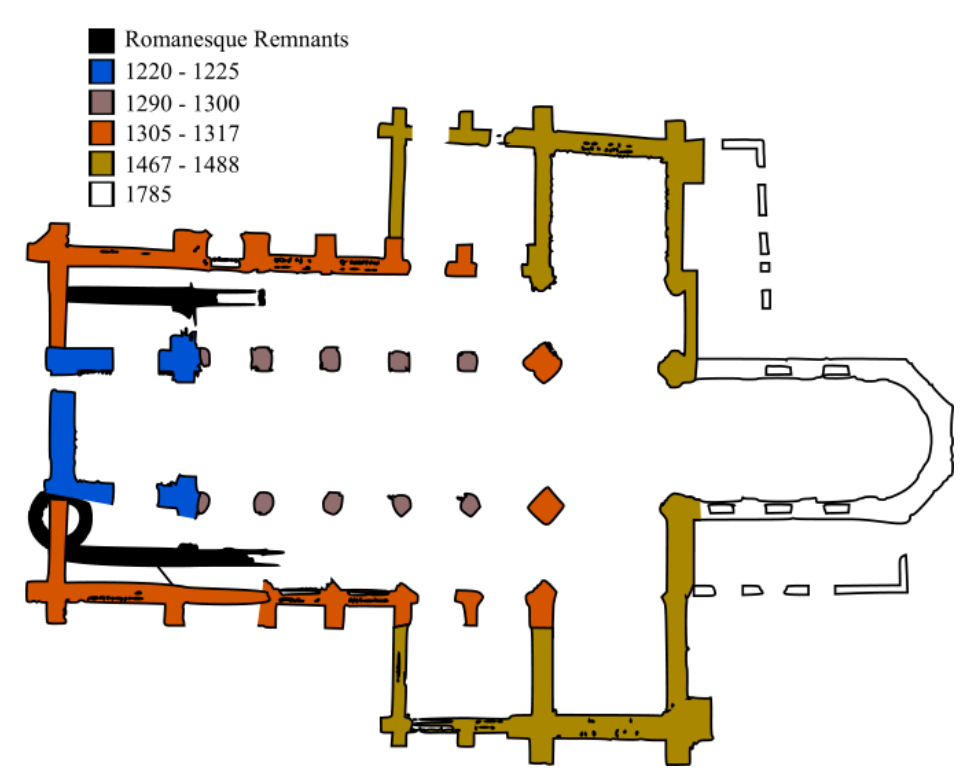

Figure 1 Church floor plan and construction phases. Adapted from [6].

\section{$147 \quad$ 2.2 Damage Survey}

148 The differential settlements in the church, which are the cause of the clear majority of structural damage, are 149 caused by the building being erected in a swamp area near the river Voer, coupled with the initially unplanned 150 addition of a second and third level, resulting in a severe increase in self-weight. The substitution of the original 151 flat timber ceiling with a wooden barrel vault and, later, a masonry vault resulted in further increase in the self152 weight.

The present study focuses on the damage documented in the northern wall of the main nave. An elevation view, the main structural elements and damage, along with the notation used for their designation, is shown in

155 Figure 2. The nave wall measures approximately $26 \mathrm{~m}$ in length and $21 \mathrm{~m}$ in height. The pathology of the nave, consisting primarily of cracks caused by differential settlement, has been documented both with hand drawings and photographically during site visits, and more recently using semi-automated point-cloud data processing [10]. 


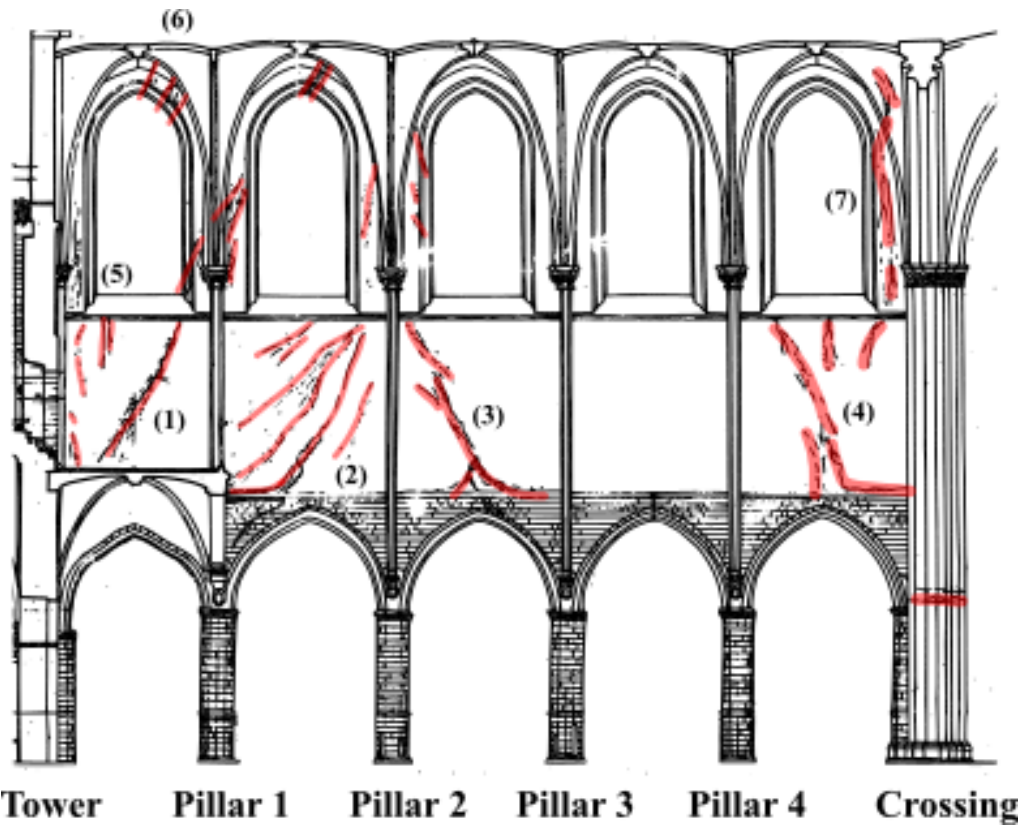

Figure 2 Northern wall of main nave: structural element designation and documented major cracks 160 indicated in red (adapted from a hand-drawn survey of the building's geometry and pathology carried out 161 by students of the Raymond Lemaire International Centre for Conservation, 1983-1984 [11]).

The arithmetically designated cracks 2 through 4 of the nave have been photographically documented and are

163 shown in Figure 3. Continuous visibility of cracks 1 through 4 is not possible due to the obstruction caused by the organ loft near the western tower. Despite the time passed between the survey in 1983-1984 (Figure 2) and the photographic survey in 2018 (Figure 3), there does not appear to be any lengthening of the major cracks. The same cannot be said with certainty about the crack widths, however, since these were not measured in the prior case. 


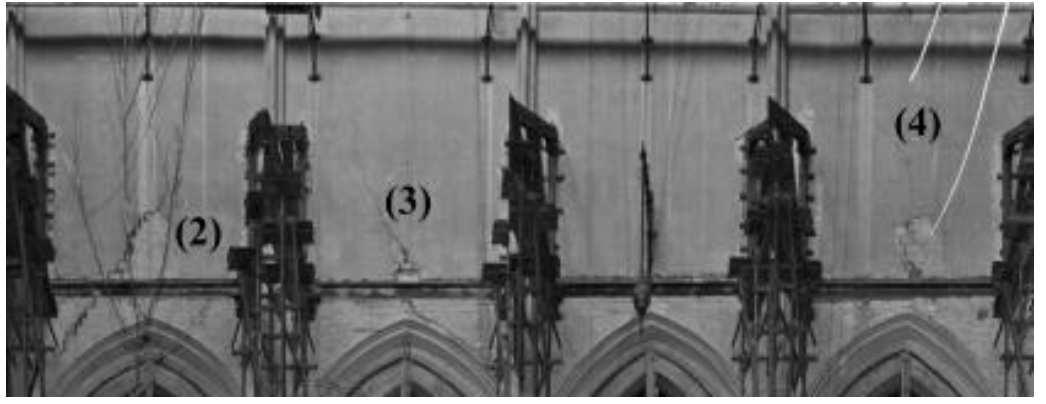

Figure 3 Photographic survey of northern nave wall cracks. View of cracks above nave pillars (photo by Pepijn Szekér, 2018). presents a crack width of a few $\mathrm{mm}$, the crack width on the masonry behind the plaster is roughly between $10 \mathrm{~mm}$ and $20 \mathrm{~mm}$ (i.e. eroded mortar joints), Figure 4. The cracks appear to mostly pass through the mortar joints rather than splitting the masonry stone units in the investigated area.

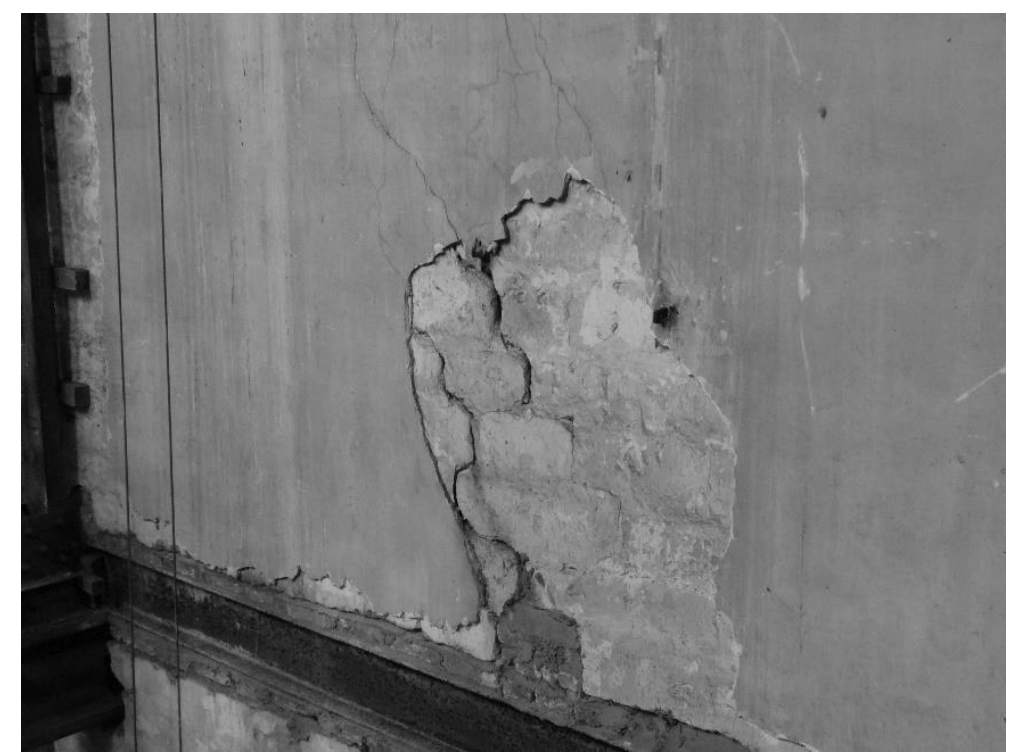

Figure 4 Close-up of cracks 4 on main nave wall (photo by Els Verstrynge, 2018).

\subsection{History of Settlements: Estimation and Geomatic Data Processing}

An estimation of the soil settlements for different parts of the structure, under different calculated loads, has 
179

180

181

182

183

184

185

186

187

188

189

190

191

192

193

194

195

property of KU Leuven [11]. These settlements are presented for the tower, crossing and pillars in Figure 5 and have been calculated based on cone penetration tests and evaluation of the soil consolidation progress according to Terzaghi, Buisman and Koppejan [12]. The results are not differentiated between individual pillars, thus rendering the calculation of the differential settlement between pillars impossible. Since the tower was completed before the beginning of the construction of the nave, an additional graph of the development of the tower settlement is provided. This graph ignores the settlements occurred before the completion of the nave wall (see grey line in Figure 5).

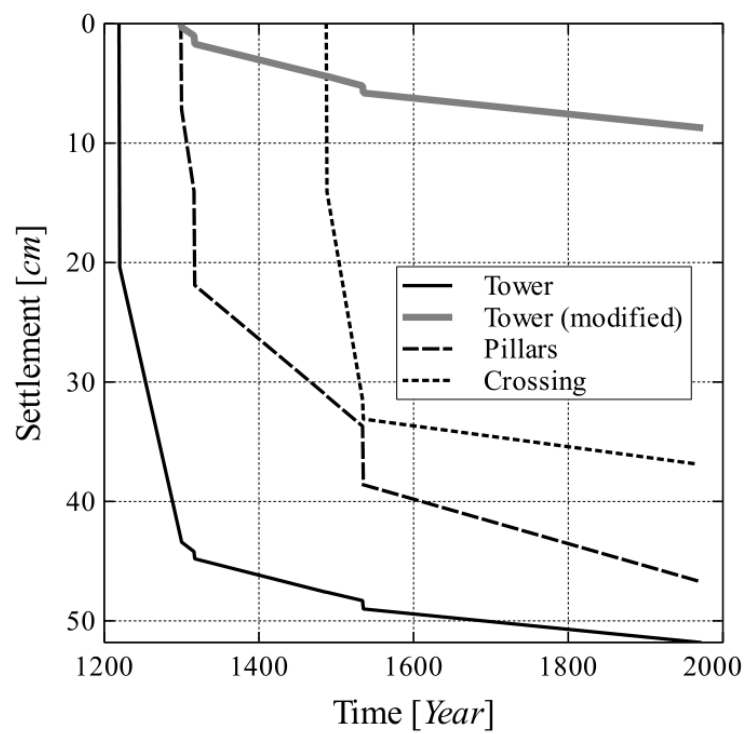

Figure 5 Calculated settlements for different structural components of the tower and nave from 1220 to 1970 (adapted from [11]).

Concerning more recent ground movement and the resulting differential settlement of the pillars, levelling surveys conducted over the previous two decades provide info on the development of differential settlements over selected periods of measurements. Contour plots of the settlements over the period 1994-2005 are presented in Figure 6. These geodetic survey results are presented in terms of settlement relative to a point in the choir which is considered, due to the absence of apparent damage, stable. The maximum settlement over this period was measured at the area around pillars 1 and 2 of the northern nave, with areas at the southern nave and northern transept presenting some uplifting. The settlement at pillars 1 and 2 is consistent with cracks 1,2 and 3 as indicated 

period 2000-2005 the settlement of pillar 2 appeared to increase at a faster rate than the other points in the nave.

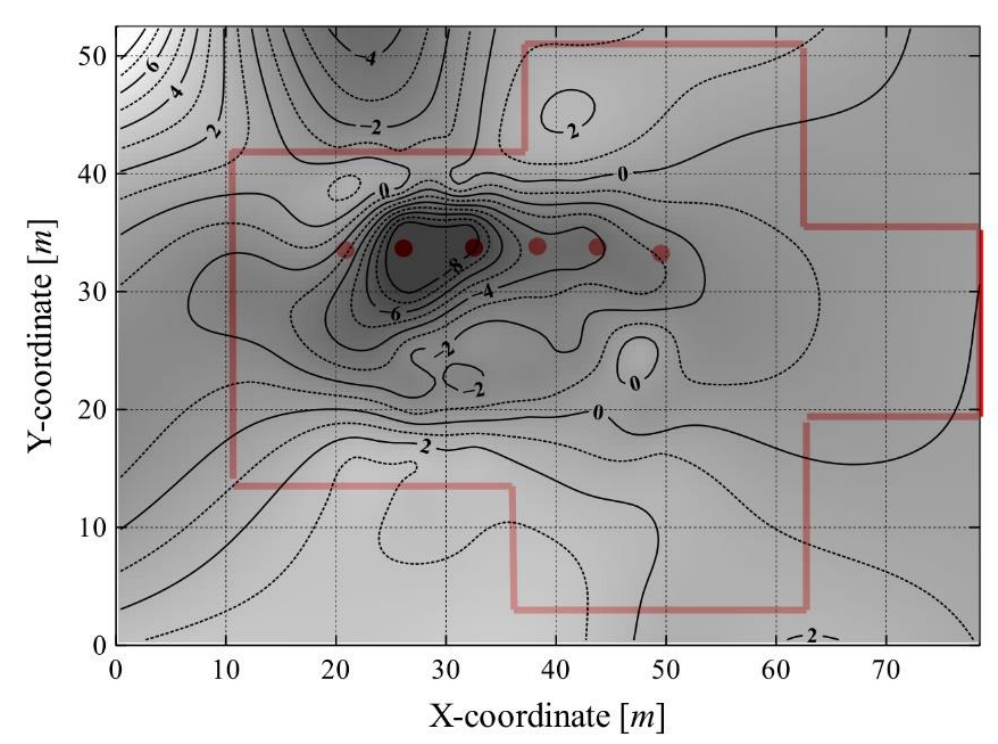

200

in Figure 2, although the time of the first appearance of these cracks is not known with certainty. It is interesting to note that all points along the nave exhibited a rather uniform settlement in the period 1994-2000, while in the

Figure 6 Contour plot of ground settlement in $\mathrm{mm}$ during the period 1994-2005 against church architectural outline. Location of northern nave from tower pilaster to crossing indicated by solid hatch circles.

An additional third approach may be adopted for the evaluation of the differential settlements over the entire history of the church. This is accomplished through the study of the geometric disposition of characteristic architectural features present on the structural elements. This approach is based on detailed laser scanning data acquired in the context of this investigation [10]. The downside of this rough approach is the inability to evaluate the total settlement that each element has undergone: only the final differential settlement can be estimated. Five reference features are chosen for this approach, from top to bottom: 1) the top of the third level arches' voussoirs, 2) the base of the pilaster abacus of the third level, 3) the top of the first level arches' voussoirs, 4) the base of the pillar abacus of the first level and 5) the top of the first level pillar pedestals. Assuming that features 1-2, and similarly 3-4-5, were built at the same period, it follows that they were, in all probability, vertically level at the time of construction. 
The measured vertical displacements relative to pillar 1 (lines 2, 4-5) or arch 2 (lines 1, 3) are shown in Figure

214 7. All architectural features are present in pillar 1 and its neighboring arch span, hence the choice of these elements as a reference, instead of, for example, the crossing column. The obtained profile is similar to the profile found in the recent leveling measurements, with the settlement being mostly concentrated around pillars 1 and 2 . This is consistent with the formation of cracks 2 and 3 (Figure 2). Differences in the profile at different heights of the structure are expected for two reasons: a) differential settlement generally affects the lower parts of the building more severely and b) the second and third levels of the nave wall were constructed at a later phase, when part of the settlements of the colonnade had already occurred.

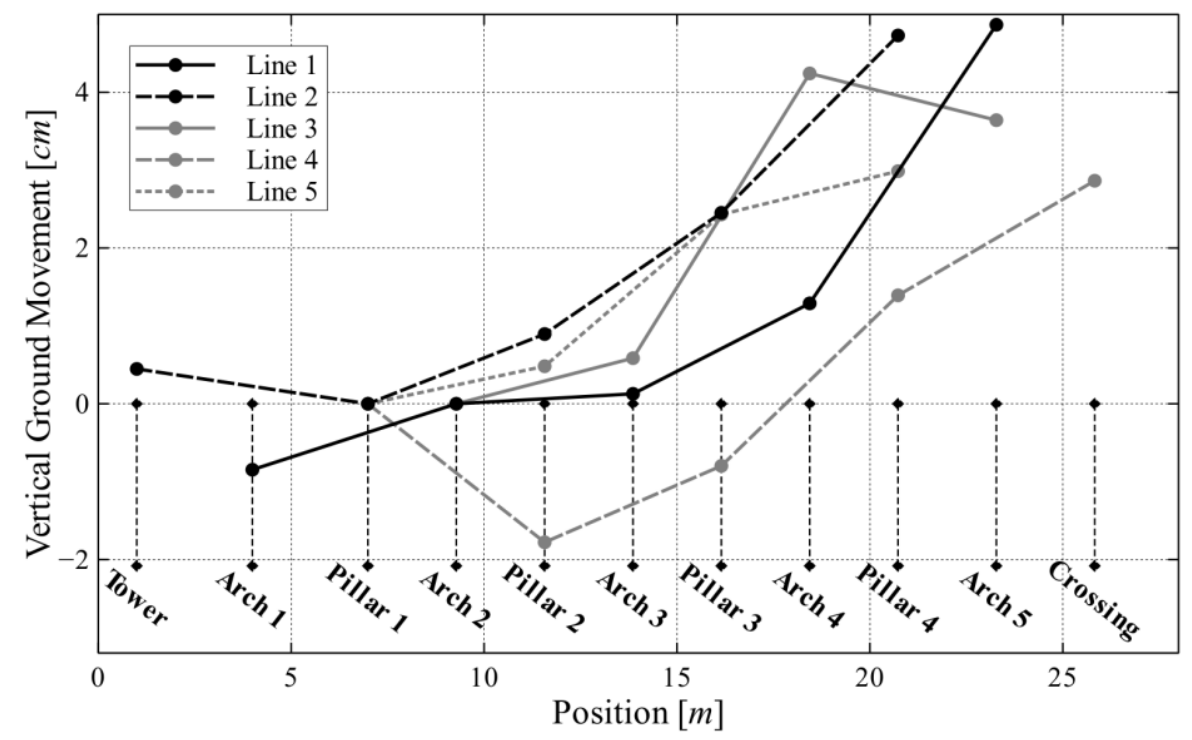

Figure 7 Differential settlements relative to pillar 1 (position: $6.99 \mathrm{~m}$ ) measured from point cloud

data architectural feature analysis. Position distance measured from tower pilaster.

\section{Analysis Procedure}

\subsection{Modeling the Nave Wall}

The geometry of the nave is derived from an idealization of the in-situ geometry in its undeformed state. A distinction is made between the three-leaf masonry of the nave wall and the solid stone masonry of the lower part of the pillars, each with its own set of material properties. The basic values of the material properties used for the 
numerical analyses, in part determined in previous experimental efforts [6,7] and in part assigned nominal or empirical values as proposed in the relevant literature $[13,14]$, are summarized in Table 1.

\section{Table 1 Basic material properties used in numerical analysis.}

\begin{tabular}{|c|c|c|c|c|c|c|}
\hline & $\begin{array}{c}E \\
{\left[\mathrm{~N} / \mathrm{mm}^{2}\right]}\end{array}$ & $\begin{array}{c}v \\
{[-]}\end{array}$ & $\begin{array}{c}\rho \\
{\left[\mathrm{kg} / \mathrm{m}^{3}\right]}\end{array}$ & $\begin{array}{c}f_{c} \\
{\left[N / \mathrm{mm}^{2}\right]}\end{array}$ & $\begin{array}{c}f_{t} \\
{\left[\mathrm{~N} / \mathrm{mm}^{2}\right]}\end{array}$ & $\begin{array}{c}G_{f} \\
{[\mathrm{~N} / \mathrm{mm}]}\end{array}$ \\
\hline Wall masonry & $3000^{c}$ & $0.15^{\mathrm{c}}$ & $1920^{b}$ & $6.99^{a}$ & $0.10^{\mathrm{c}}$ & $0.012^{\mathrm{d}}$ \\
\hline Pillar masonry & $15700^{b}$ & $0.20^{b}$ & $2360^{b}$ & $11.95^{a}$ & $1.00^{\mathrm{d}}$ & $0.075^{\mathrm{d}}$ \\
\hline \multicolumn{4}{|c|}{$\begin{array}{l}\text { a: experimentally derived value [6] } \\
\text { b: experimentally derived value [7] }\end{array}$} & \multicolumn{3}{|c|}{$\begin{array}{l}\text { c: estimated value [13] } \\
\text { d: estimated value [14] }\end{array}$} \\
\hline
\end{tabular}

The masonry walls and columns of the nave are modeled using 8-node quadrilateral and 6-node triangular plane stress elements, an approach suited to the geometric arrangement, element thickness and load orientation. A macro-modeling approach is adopted for the model, in which the masonry composite is treated as a homogenous continuum, with no distinction between units, mortar and the unit-mortar interface. The nonlinearity in tension is modeled using a multi-directional fixed crack model. A Rankine-type tension cut-off is used in pure or biaxial tension, while the influence of lateral compression is accounted for through a Mohr-Coulomb-type criterion.

$$
\sigma_{t}=\left\{\begin{array}{ccc}
f_{t}\left(1-\frac{\varepsilon_{c r}}{\varepsilon_{u}}\right)^{0.31} & \text { for } & 0 \leq \varepsilon_{c r} \leq \varepsilon_{u} \\
0 & \text { for } & \varepsilon_{u} \leq \varepsilon_{c r}<\infty
\end{array}\right.
$$
expression [15]:

$$
\varepsilon_{u}=4.226 \frac{G_{f}}{f_{t} h}
$$

where $h$ is the characteristic length of the finite element. 


\subsection{Foundation and Soil-Structure Interaction}

Soil-structure interaction is directly considered through the introduction of linear elastic structural interfaces at the base of the masonry pillars, capable of accounting for normal and shear deformation. The normal stiffness may be determined according to two distinct approaches: (a) from a calibration effort targeted at reproducing the settlement profile measured over a given time period and (b) directly from the geometric characteristics of the pillar footing and the elastic properties of the soil.

Both approaches are adopted and compared in the present paper. The values obtained from approach (a) are presented in the results section. For approach (b), the vertical elastic spring constant for a single rigid arbitrarily shaped footing $j$ circumscribed in a rectangle with dimensions $2 L^{j} \cdot 2 B^{j}$ and embedded in the ground at a depth of $D^{j}$ is equal to [16]:

$$
K_{n}^{j}=\frac{2 G L^{j}}{1-v}\left(0.73+1.54 x^{0.75}\right)\left[1+\frac{1}{21} \frac{D^{j}}{B^{j}}(1+1.3 x)\right]\left[1+0.2\left(\frac{A_{w}^{j}}{A_{f}^{j}}\right)^{2 / 3}\right]
$$
is the total sidewall-soil contact area (equal to the perimeter of the footing times the embedment depth $D^{j}$ in case of a foundation with constant cross-section) and $x=A_{f}^{j} /\left(2 L^{j}\right)^{2}$. Division of the spring constant by $A_{f}^{j}$ produces the modulus of subgrade reaction for a single footing:

$$
k_{n}^{j}=\frac{K_{n}^{j}}{A_{f}^{j}}
$$

This value is used for the normal stiffness of the interfaces below the pillars, adjusted according to the ratio of the base area of the footing over the cross-sectional area of the pillar at ground level. The settlement $d_{n}^{j}$ of the 258 foundation for a given normal force $F_{n}^{j}$ is: 


$$
d_{n}^{j}=\frac{F_{n}^{j}}{K_{n}^{j}}
$$

The value for the shear stiffness of the interface is calculated by the expression:

$$
k_{s}^{j}=\frac{k_{n}^{j}}{2(1+v)}
$$

according to the Poisson's ratio $v$ of the stone masonry foundation. This value is not determined experimentally but is consistent with the material properties of the stone masonry and is numerically more stable and less arbitrary than the use of a dummy value that precludes shear slipping at the foundation. This slipping mode is, in any case, constrained by the high compressive stress applied on the interface by the self-weight and the lack of horizontal loads. Therefore, the shear stiffness is calculated for a Poisson's ratio of 0.20 without further investigation.

The soil beneath the church foundations has been investigated and found to be generally composed of, from the surface advancing in depth: a) sandy clay ( $\pm 2.0 \mathrm{~m}$ thick$),$ b) highly compressible peat $( \pm 2.0 \mathrm{~m}$ thick$)$, c) sandy clay ( $\pm 2.6 \mathrm{~m}$ thick), d) quaternary clay-containing sand ( $\pm 5.4 \mathrm{~m}$ thick) and e) tertiary highly consolidated claycontaining sand (unknown thickness) [6]. The foundation bases of the main pillars are roughly in the middle of the peat layer. In the present case study, the settlements have been calculated prior to this investigation. Therefore, the interface normal stiffnesses can be directly calculated from eq. (5) and (4). Using eq. (3) the apparent Young's modulus of the homogenized foundation soil can be back-calculated. In the case of the nave pillars at the final settlement (as shown in Figure 5) this apparent Young's modulus is equal to $0.597 \mathrm{~N} / \mathrm{mm}^{2}$ or $2.400 \mathrm{~N} / \mathrm{mm}^{2}$ when taking into account or disregarding the effect of embedment respectively. The former value is representative of peats, while the latter is rather low for the all the soils in the other layers. This indicates the major contribution of the peat layer to the total settlements and the potential primary cause of the excessive settlements of the church at the nave. 
For all analysis cases, the structure is let to deform under its self-weight and the extra load applied at various levels of the nave wall from other elements present in the structure but not explicitly modeled, such as the timber roof or the stone masonry vaults.

All finite element calculations were carried out using the DIANA FEA package [17]. The geometric layout and the boundary conditions applied are illustrated in Figure 8. The different phases are colored in shades of grey and the areas where pillar masonry material is assigned are given a reddish overlay. It is assumed that the tower to the west of the nave (left side in the illustration) provides a rigid lateral support to the nave. The average element length is roughly $166 \mathrm{~mm}$, resulting in a total of 40308 nodes and 13029 continuum and 37 interface elements.

The roof loads associated with each of the three phases is applied at the top of every model.
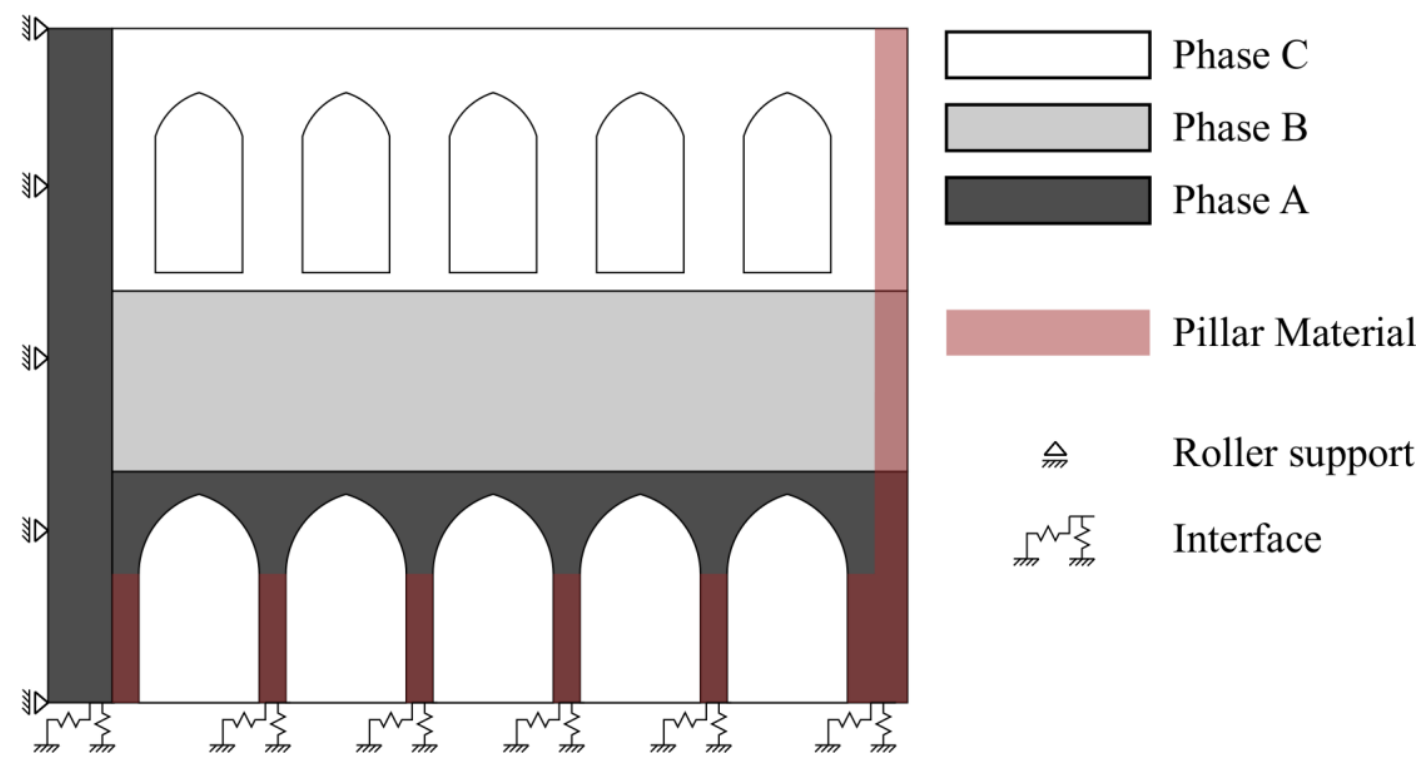

公 Roller support

Interface

Figure 8 Geometric layout of church nave wall. Structural phase designation, boundary conditions and material assignment.

\subsection{Definition of Time Periods for Phased Analysis}

Three different time periods are defined for the investigation of the time-dependent behavior of the building: period A (1300-1316), period B (1317-1534) and period C (1535-1970), which coincide with the construction 
The end of period A corresponds to the initiation of the increase of the height of the nave and period B starts upon its completion. The end of period B corresponds to the construction of the crossing and the third level of the nave wall. Period $\mathrm{C}$ brings us near to the present period, at the time of major temporary shoring of the building. calculate the normal interface stiffness, and also back-calculate the apparent Young's modulus of the soil at given is shown in Figure 9. This value is proportional to the apparent Young's modulus of the soil. One can differentiate between a short-term Young's modulus, governed by immediate settlements due to a change in load, and a longterm Young's modulus, governed by settlements due to, for example, consolidation. In the case of the pillars, the short-term Young's modulus generally exhibits a decreasing trend, whereas the long-term modulus exhibits an increase. The two curves appear to converge near the end of the measurement period, indicating that processes causing settlement under sustained loads have been halted. The consolidation being further completed accounts for the latter phenomenon, but the continuation of the settlements cannot be entirely excluded.

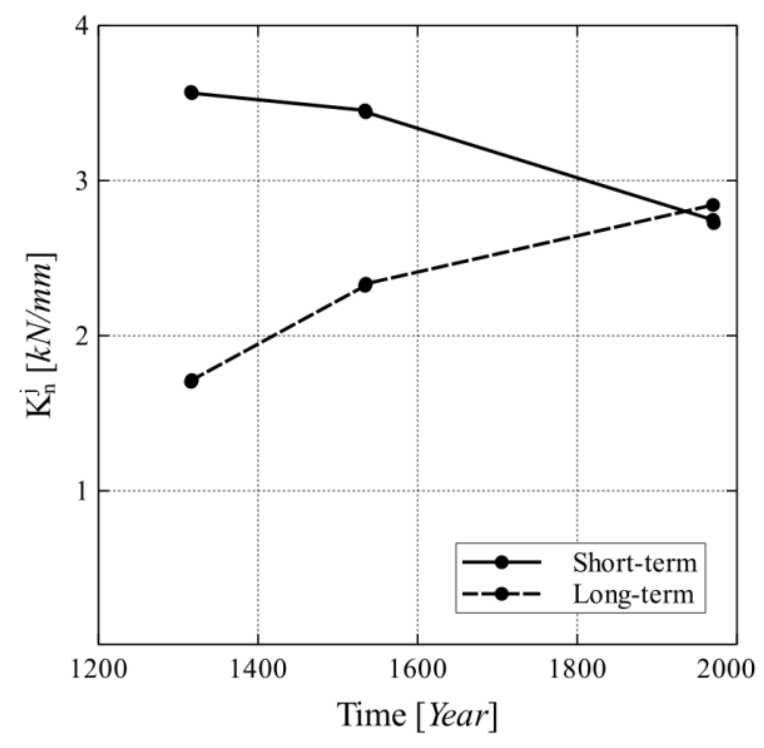




\subsection{Analysis Approaches}

312 Three different approaches will be adopted for the analysis of the nave: a single-phase analysis, a phased 313 analysis and a parametric study.

Firstly, in the single-phase analysis, the whole structure is taken in its entirety and the foundation interfaces are assigned their final values according to the estimated settlements of each structural part and the dimensions of the footings.

Secondly, in the phased analysis, three major phases are considered, with each one decomposed into two parts.

The major phases correspond to the phase designation indicated in Figure 8 and the decomposition of each phase is based on the differences between the short-term (immediate) and the long-term response of the structure under the sustained loads of each phase. Both the single-phase analysis and phased analysis make use of approach (b) for determining the interface normal stiffness as explained in Section 3.2.

Thirdly, a parametric analysis is performed to address uncertainties in the mechanical properties of the materials. In order to reduce the computational cost, these analyses are only carried out for the settlement profile obtained from the levelling surveys of the period 1994-2005. Such analysis is defined in Section 3.2 as approach (a) for determining the normal stiffness. In the following section, this choice of loading is motivated further, through a discussion of the obtained failure patterns. The material parameters included in the investigation are the Young's modulus, the tensile strength and the tensile fracture energy of the masonry composing the nave. The variation of the parameters ranged from $50 \%$ to $200 \%$ of the initial values indicated in Table 1 . The model using the initial values will be henceforth referred to as the reference model.

\section{Analysis Results}

\subsection{Single-Phase Analysis}

As a first approach, the self-weight of the complete structure along with the final additional roof weights is applied in a single phase. The final value for the stiffness of the foundation interfaces is used (see Figure 9), corresponding to the long-term soil modulus of phase $\mathrm{C}$. The obtained crack pattern is shown in Figure 10. The 
obtained damage pattern presents several differences from the actual structure. Due to the settlement towards the crossing, the response is dominated by the separation cracks between the nave and the tower. Crack 2 above arch 2 (Figure 2) is entirely absent. A single crack is formed between pillars 2 and 3 (crack 3, but inclined in the other direction) and the crossing itself remains intact, as does its connection with the wall. Therefore, application of the deformation loads in a single analysis step reveals only part of the response of the building and is not indicative of its behavior throughout its history.

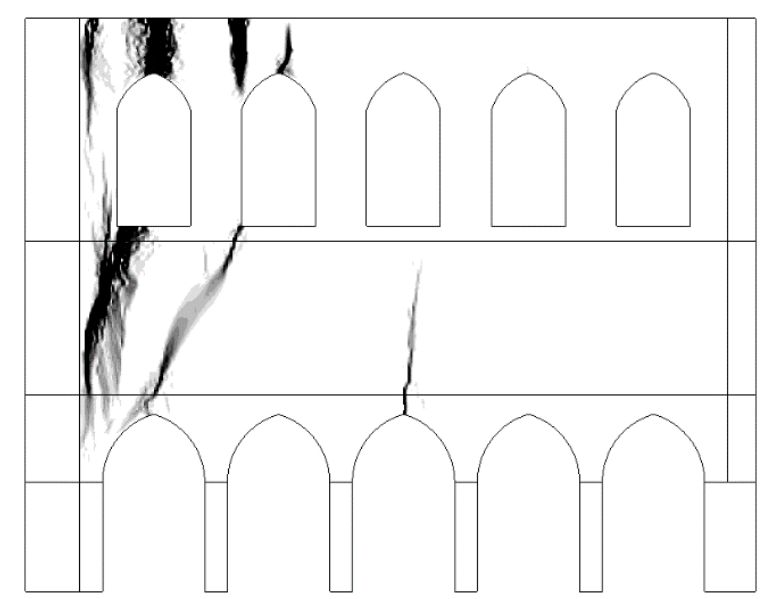

Figure 10 Crack patterns for application of load in single analysis phase.

\subsection{Phased Analysis}

The phased analysis of the nave provides a much more complete and detailed illustration of the development of damage on the building throughout its history (Figure 11). The obtained settlement profiles derived from the phased analysis, as well as from the single-phase case, are presented in Figure 12.

During phase A, only minor damage is registered at arches 1 and 5, see Figure 11a. There is some widening of the cracks under long-term loading, but no formation of new major cracks, see Figure 11b. The response is mostly of a sagging type due to the tower and the crossing exhibiting only minor settlement. Due to the numerical cracks not having sufficiently developed in extent, no clear comparison between the numerically derived cracks and the existing damage in the building can be made. 
The situation changes significantly during phase $\mathrm{B}$ with the increase of the height of the nave wall above the

colonnade. A major separation crack is formed in the short-term phase between the tower and the nave (cracks 1 and 5). Additionally, cracks 2 and 3 are formed above pillar 3. At the end of the long-term loading, cracks 1 and 4 have emerged above the main colonnade. While the settlement profile is mostly of a sagging type at the end of the short-term phase (Figure 12), a mixed profile with a significant tilting component is obtained at the end of the long-term phase. The increase of the weight at the crossing is substantial and unable to be borne by its foundations.

Phase $\mathrm{C}$ witnesses the formation of the new cracks above and beside the third level windows (cracks 6 and 7 in Figure 2). The extent of the previously formed cracks is increased without, however, significant widening, indicating the activation of the cracks at the new parts of the structure. As shown in Figure 12, the obtained profile resembles the tilting-dominated response at the end of phase $\mathrm{B}$, but of a larger magnitude.

In Figure 12, the maximum settlement obtained at the end of the phase $\mathrm{C}$ closely resembles that of the singlephase analysis, albeit with a slightly smaller magnitude. Nevertheless, the cracking pattern is significantly different in the two approaches. The resulting cracking pattern from the phased analysis resembles in a higher degree the actual pattern (compare Figure 2 and Figure 11). The cracking pattern resulting from the phased analysis resembles much more closely the actual crack pattern compared to the single-phase analysis (compare Figure 10 and Figure 11). The complexity of the model, as the outcome of soil-structure interaction, is underlined by the substantially different settlements obtained between the four pillars. This is despite the fact that they are of the same crosssection with identical foundations (meaning equal interface stiffness) and bearing roughly the same vertical loads.

Overall, as time progresses, the deflection ratio of the structure tends to decrease, despite the increase in the overall settlements (Figure 12). Cracks 2 and 3, caused by the sagging of the center are nearly fully developed by the end of phase $\mathrm{B}$, after which newly arising damage is possibly associated with tilting of the nave towards the crossing. The maximum width of the cracks in the first level of the wall in fact decreases from phase B to phase C due to the stabilizing effect of the added stiffness of the second level and despite the increase in weight. 
a)

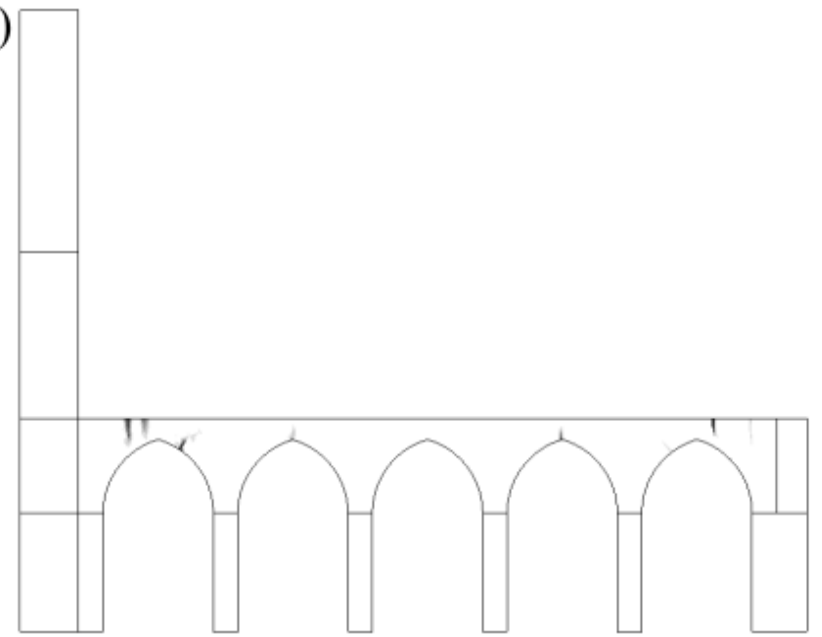

c)

(5)

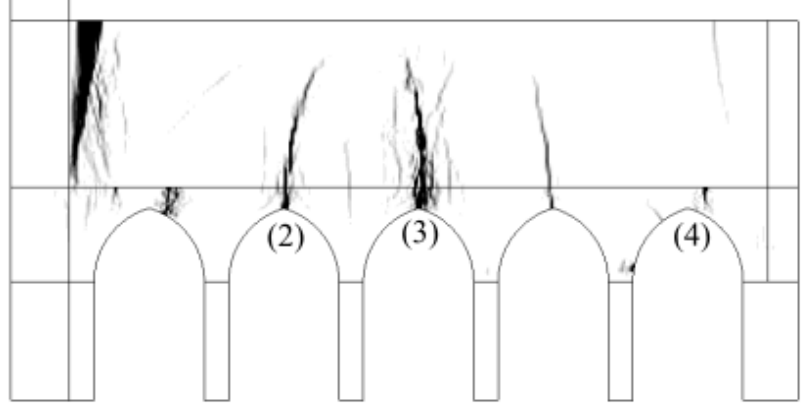

e)

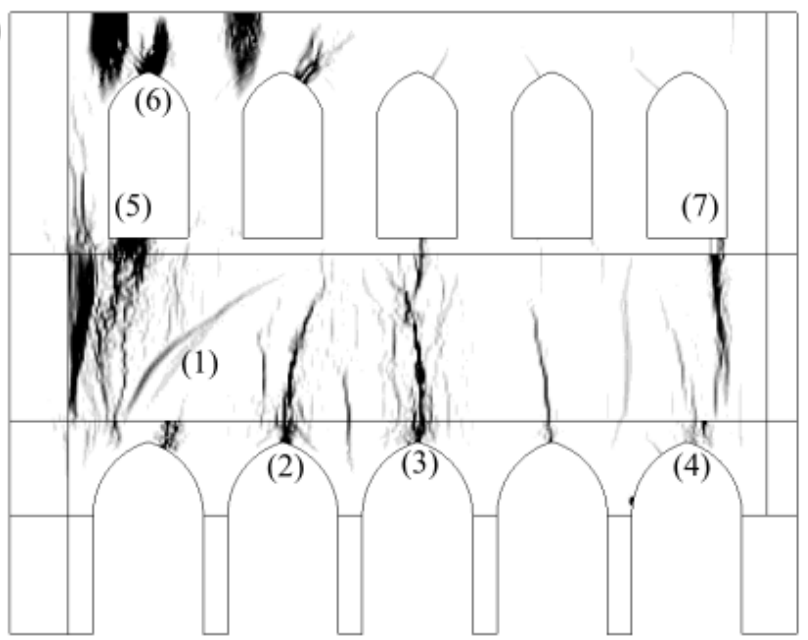

b)

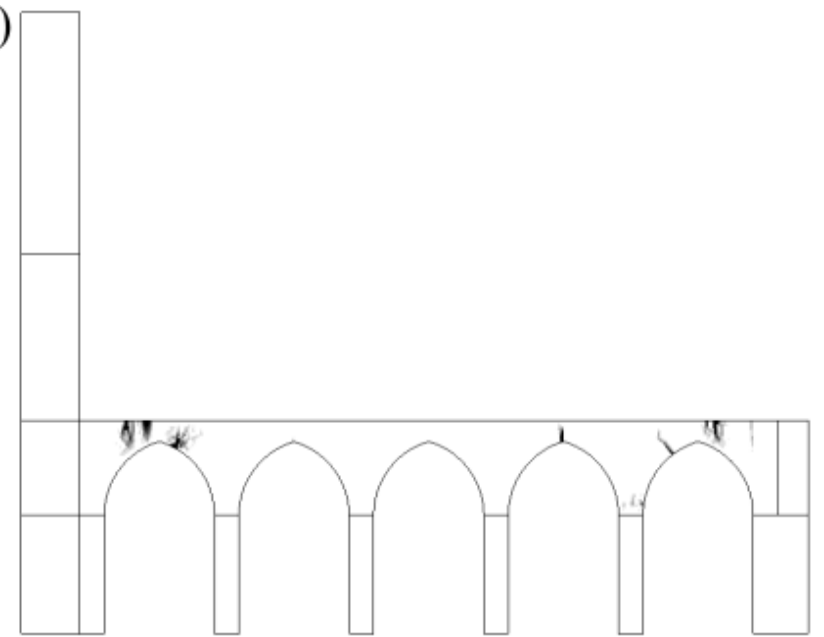

d)

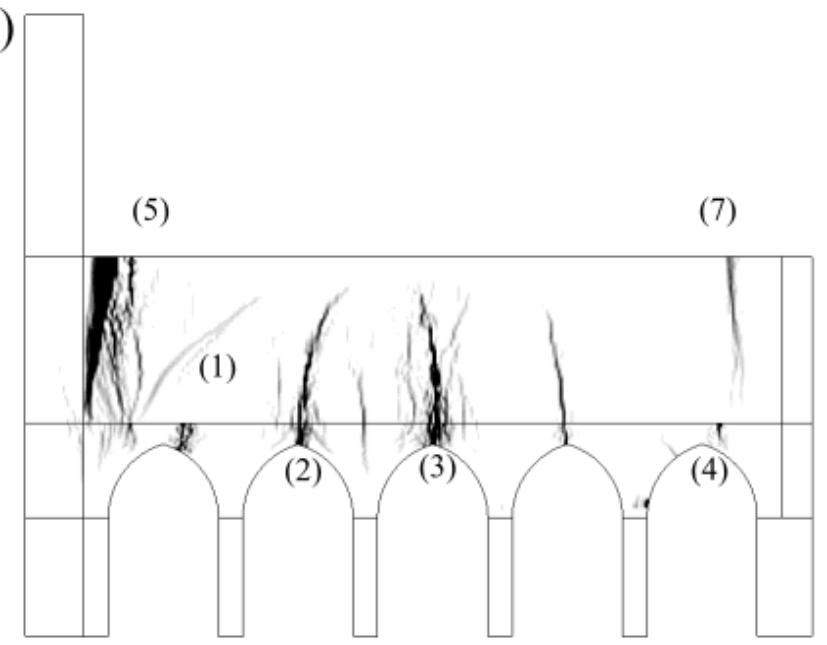

f)

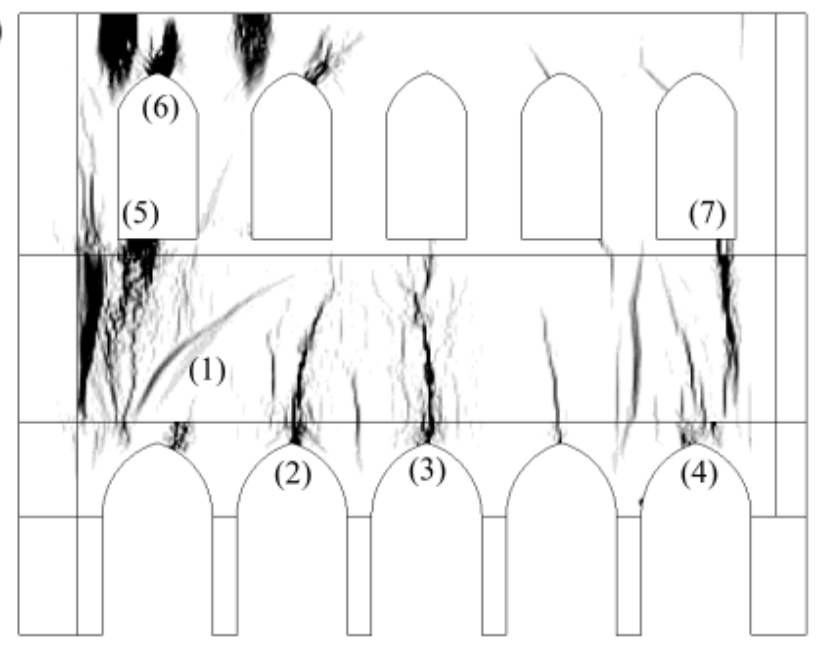

Figure 11 Crack patterns for phased analysis of nave: a) phase A short-term, b) phase A long-term, c) phase B short-term, d) phase B long-term, e) phase C short-term, f) phase C long-term. 


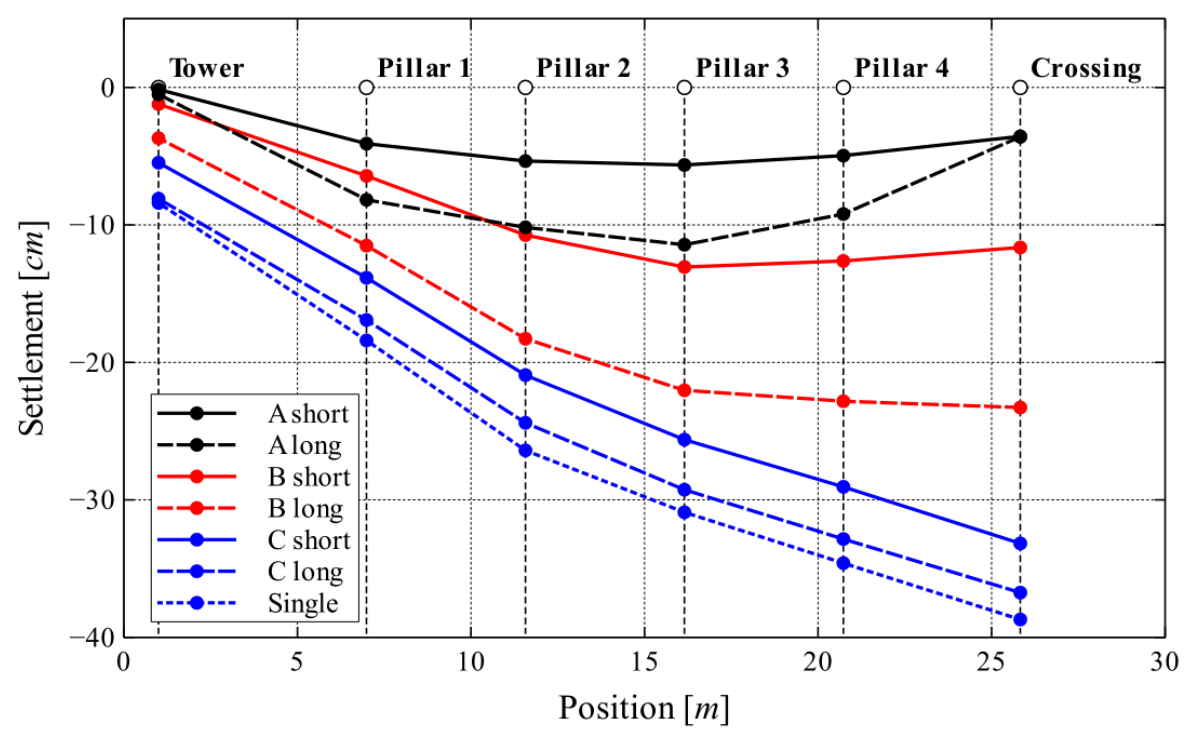
approaches.

The numerically obtained cracks have been matched to cracks documented in the structure (Figure 2 and Figure 11). Rather than integrating the obtained crack strains over the continuum to calculate the crack width, the opening of the cracks is indirectly calculated through measurement of the horizontal relative displacements of nodes on either side of the smeared crack mouth. Displacements due to elastic stress are minimal compared to displacements due to crack opening. In cases where the cracks in the actual structure are composed of more than one distinct branch, this measured numerical crack width is divided by the number of branches in order to obtain the magnitude of a single crack branch. The development of the normalized crack width, defined as the sum of the crack width divided by the number of crack branches in the actual structure, is presented in Figure 13. All cracks tend to increase with the passage of time, except crack 3, which is reduced in width after the construction of the second and third level of the nave. 


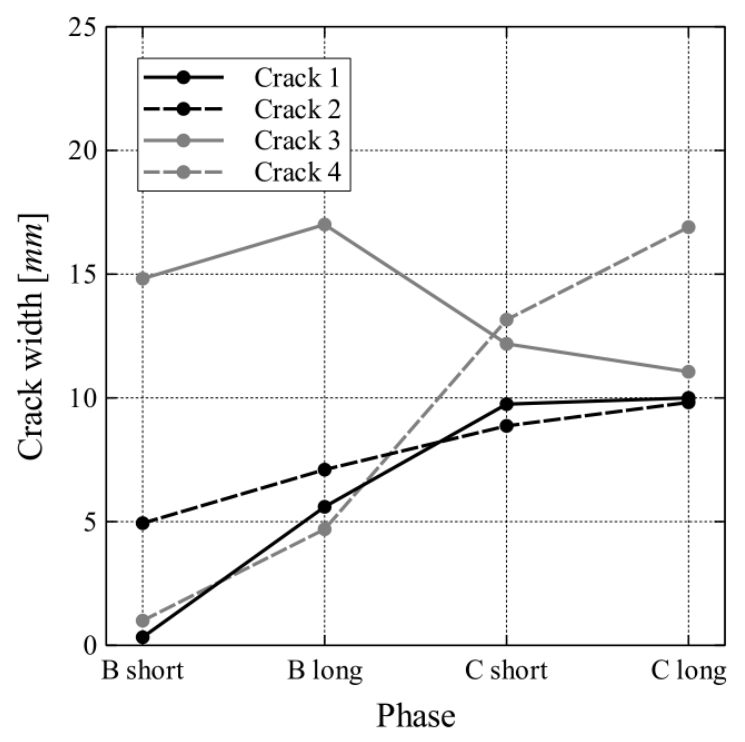

Figure 13 Normalized crack width for various analysis phases.

393

\subsection{Parametric Investigation}

The damage pattern obtained from the reference model is shown in Figure 14. This is the outcome of the application of the settlement pattern measured in the period 1994-2005. Rather than the displacement being applied to the supports directly, the stiffness of the interfaces was calibrated in order to match this settlement profile. This approach allows the evaluation of the soil-structure-interaction by altering the settlements from a variation of the stiffness of the superstructure.

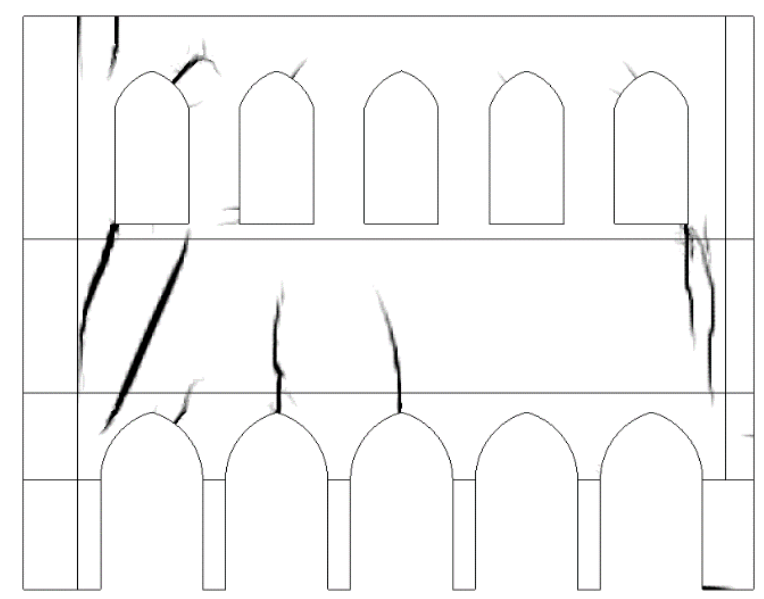

Figure 14 Crack pattern obtained from the reference model of the parametric investigation. 
Despite the narrow extent of this measurement period compared to the entire history of the building, the pattern closely resembles the damage present in the structure, both in location and extent, albeit with a much smaller magnitude in terms of crack width. This constitutes an indication that the emergency measures taken from 1965 onwards may have not completely halted the progress of settlement in the structure. Nevertheless, this resemblance motivates the use of this measured profile as a basis in the parametric investigation carried out in this section.

The results of the parametric investigation are illustrated in Figure 15. They are presented in terms of the width of cracks 2 and 3 vs. settlement of pillar 2, above which the cracks in question are situated. Initially, the Young's modulus of the pillar was investigated, due to the initially determined value being higher than expected given the compressive strength of the pillar masonry (see Table 1). The change in the Young's modulus of the pillar does not significantly affect the response of the nave, due to the limited extent of the nave area in which it is encountered.

412 However, the reduction of the Young's modulus of the wall increases both the width of the cracks and the amount 413 of settlement of pillar 2. Interestingly, the reduction of the Young's modulus causes crack 2 to increase in width 414 and crack 3 to be severely reduced, owing to the redistribution of forces in the wall. Cracks 2 and 3 are differently 415 affected by changes in the tensile strength of the wall masonry as well. The width of crack 2 slightly increases for 416 any change in the parameter, while crack 3 decreases, practically disappearing for a decrease in the tensile strength.

417 Finally, the response was not particularly sensitive to changes in the tensile fracture energy of the wall masonry. 418 However, a slight increase in the total settlement of the pillar is registered for a decreased value of this parameter. 

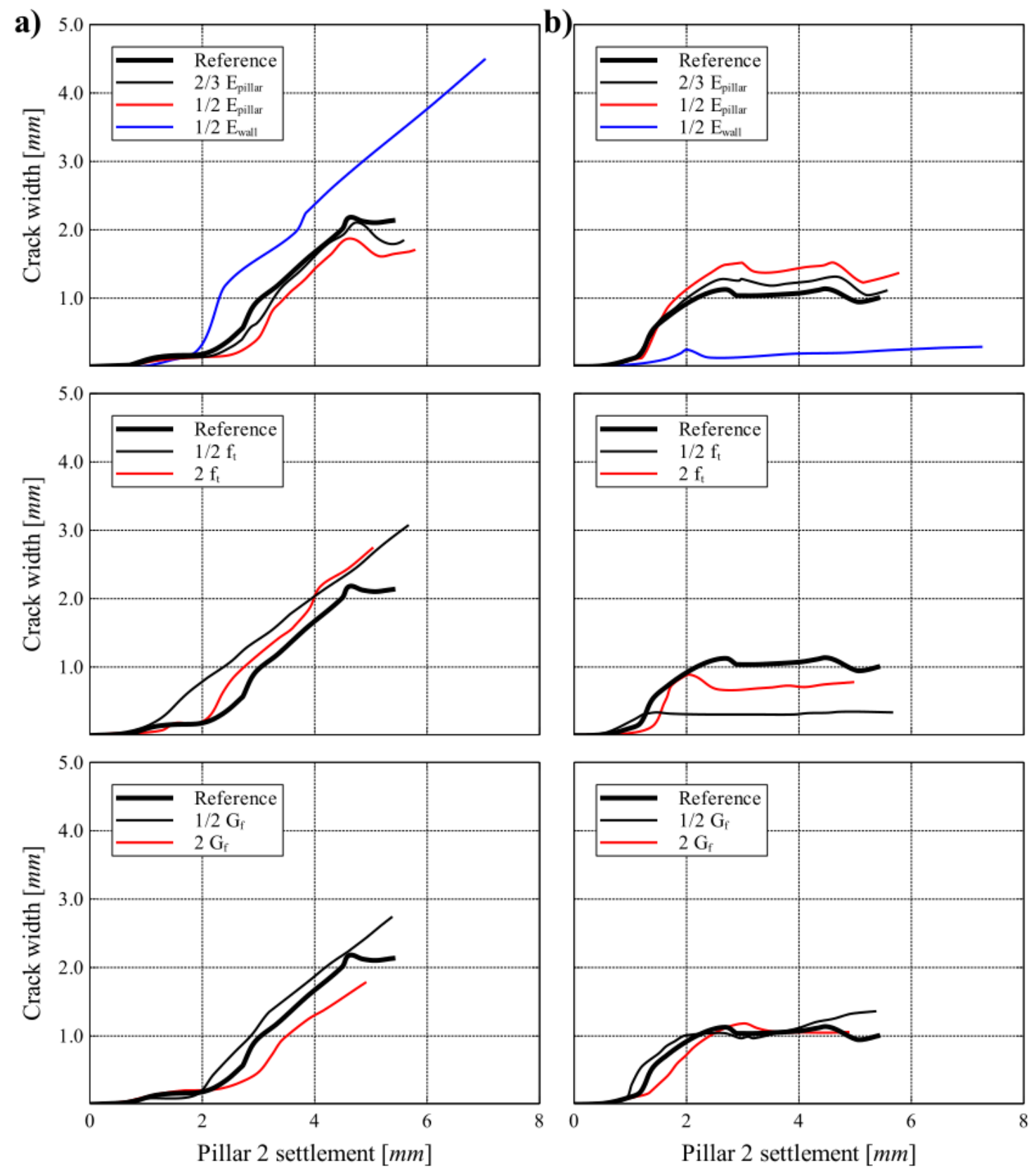

Figure 15 Results of parametric investigation for a) crack 2 and b) crack 3. Crack widths vs. variation

The results are also tabulated in Table 2, with the addition of the results of the horizontal movement and vertical settlement of pillar 2. The changes in the horizontal movement of the pillar, measured at the capital and indicating tilting rather than whole body slipping, are either associated with the crack widths above the pillar or with the capacity of the wall for post-cracking deformation (as influenced by an increase in the fracture energy). 
Crack 2 did not present strong sensitivity to the material properties. Crack 3 presented some sensitivity to the

tensile strength of masonry. The dependence on the Young's modulus of masonry is partially related to the increase of crack width due to reduced stiffness of the superstructure. The tensile fracture energy had only a marginal effect on either crack. The crack arrangement was not sensitive to the material properties. These observations suggest that crack formation and development are more sensitive to the applied deformation profile. This outcome illustrates the importance of an accurate calculation of the properties of the soil and a good measurement of the historic settlement profile in order to achieve meaningful analysis results. In light of the envisaged intervention project, consolidation of the wall masonry, which would lead to some degree of increase of the tensile strength, fracture energy and Young's modulus of the material, can be beneficial in itself for maintaining the integrity of the church and limiting the effects of possible future differential settlement. This can act as a complement to the foundation strengthening and soil consolidation underway.

Table 2 Results of parametric investigation. Percentile differences from reference model results in crack width and displacement (vertical and horizontal) of pillar 2.

\begin{tabular}{ccccc}
\hline & Crack width 2 & Crack width 3 & $\Delta x_{\text {pillar 2 }}$ & $\Delta y_{\text {pillar 2 }}$ \\
\hline Reference & 100 & 100 & 100 & 100 \\
$1 / 2 f_{t}$ & 146 & 32 & 190 & 105 \\
$2 f_{t}$ & 129 & 77 & 85 & 93 \\
$1 / 2 G_{f}$ & 129 & 137 & 76 & 99 \\
$2 G_{f}$ & 83 & 105 & 271 & 91 \\
$2 / 3 E_{\text {pillar }}$ & 85 & 111 & 97 & 103 \\
$1 / 2 E_{\text {pillar }}$ & 80 & 136 & 102 & 107 \\
$1 / 2 E_{\text {wall }}$ & 218 & 29 & 352 & 134 \\
\hline
\end{tabular}

\subsection{Discussion on Model Results}

A final appraisal of the obtained results from the modeling approaches is warranted. In particular, the results from the phased analysis need to be contrasted with the monitoring and survey data. The final deformation profile obtained for the phased analysis (Figure 12) relies on the estimation of the behavior of the soil through time. The profile estimated from the architectural features of the building (Figure 7) depicts the effects of soil-structure interaction more directly. The latter profile compares favorably with the deformation profile obtained from 
monitoring data over the period 1994-2005. The normalization of the estimated settlements by disregarding the tower movement prior to the construction of the nave wall makes a direct comparison difficult. The lack of measurements in the period 2005-2018 further complicates matters, which the new intervention project will help clarify. Finally, the analysis approach does not take into account the full three-dimensional geometry effects of the structure. These are potentially more acute near the crossing pillar due to the presence of the transept. Nevertheless, the numerical analysis approach adopted here is able to capture the response of the nave with significant fidelity.

The assumption of a uniform interface stiffness below all the pillars in the nave is a necessary simplification due to the lack of more detailed data. Despite resulting in an accurate crack pattern, the final disposition is not in complete agreement with the settlement as estimated from the architectural feature analysis. However, a more clear relation between the numerical and measured deformation profile is obtained when comparing deflection ratios. The deflection ratio is defined as the ratio of the relative settlement to the length of the deflected part. In Figure 16, the deflection ratios along feature Line 4 (base of the pillar abacus of the first level) are presented, based on the measurements shown in Figure 7. The deflection ratio along this line could be more clearly defined along a larger portion of the structure compared to other lines and is sufficiently close to the base of the pillars to provide an indication of the settlement. As Figure 16 illustrates, the deflection ratios between the two approaches are quite 460 similar, with the sagging of the colonnade between the tower and the crossing pillar being clearly indicated. 


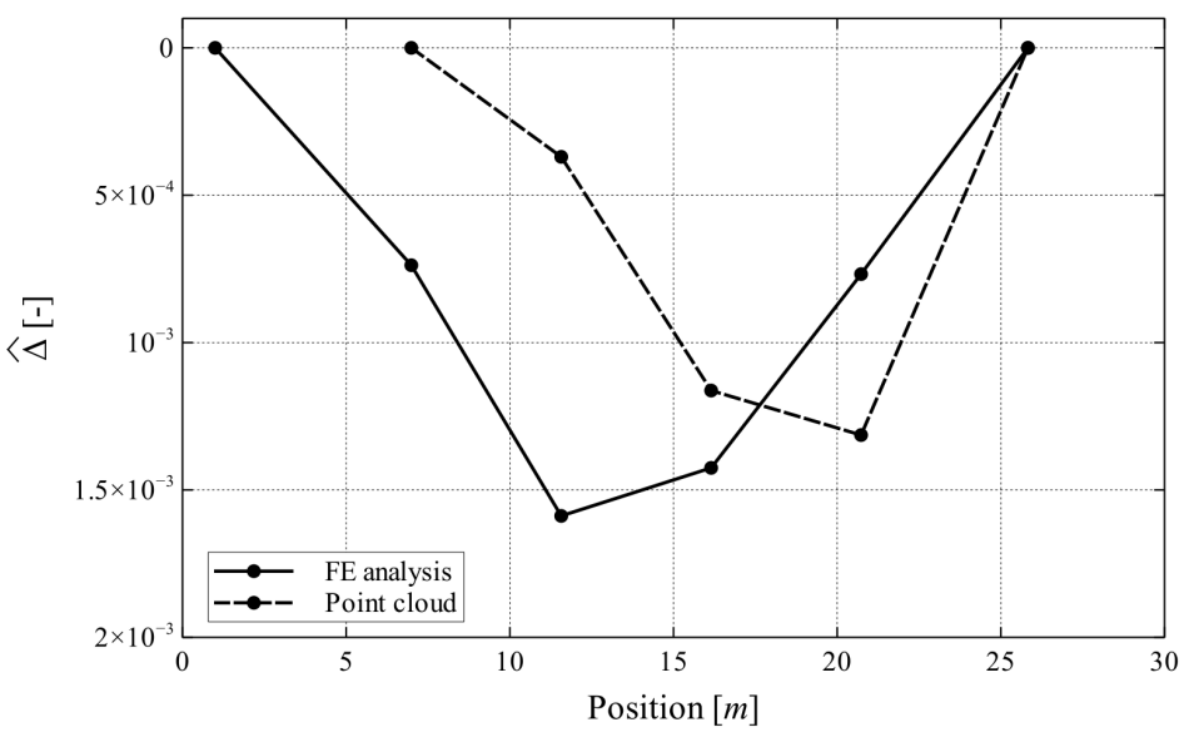

Figure 16 Comparison of deflection ratio from finite element analysis and architectural feature measurement on the point cloud (Line 4).

\section{Damage Calculation Using an Analytical Damage Function}

\subsection{Calculation of Model Parameters}

The model proposed by Giardina et al [5], which introduced an analytical relation between settlement and damage index for masonry buildings, will be adopted for the present study. The model relates the deflection ratio $\hat{\Delta}$ due to sagging or hogging ground deformation to a damage level of the structure according to the classification proposed by Burland \& Wroth [18]. The damage level, linked to the severity of damage and the means required for its repair, is quantitatively expressed in terms of crack width, thus directly comparable to both documented pathology and nonlinear finite element analysis results. The damage classes are outlined in Table 3. The damage model for two-dimensional structures is a function of several geometric and material parameters expressed in a polynomial equation as follows: 


$$
d_{2 D}^{\prime}(\hat{\Delta}, \bar{x})=d_{2 D, r e f}(\hat{\Delta})+\sum_{i=1}^{6} a_{i} \bar{x}_{i}=b_{1}+b_{2} \hat{\Delta}+b_{3} \hat{\Delta}^{2}+b_{4} \hat{\Delta}^{3}+\sum_{i=1}^{6} a_{i} \bar{x}_{i}
$$

where $d_{2 D, \text { ref }}$ are the selected reference values, $a_{i}$ and $b_{i}$ are fitted polynomial coefficients and $\overline{\boldsymbol{x}}$ contains the normalized values of the model parameters $x_{i}$. The $x_{i}$ model parameters, along with their reference values $x_{i, r e f}$ are given in Table 4. All values for the polynomial coefficients and the normalization process for the model parameters are detailed in [5]. From the value of the damage level calculated from the model, one can calculate the corresponding crack width through linear interpolation based on the values found in Table 3 .

Table 3 Damage classification for masonry structures subjected to differential settlements [18].

\begin{tabular}{|c|c|c|}
\hline Damage Level & Damage Class & $\begin{array}{c}\text { Crack Width } \\
{[\mathrm{mm}]}\end{array}$ \\
\hline 1 & Negligible & $0.0-0.1$ \\
\hline 2 & Very Slight & $0.1-1.0$ \\
\hline 3 & Slight & $1.0-5.0$ \\
\hline 4 & Moderate & $5.0-15.0$ \\
\hline 5 & Severe & $15.0-25.0$ \\
\hline 6 & Very Severe & $>25.0$ \\
\hline
\end{tabular}

Table 4 Damage model reference values $x_{i, r e f}[5]$ and input for current analysis $x_{i}$.

\begin{tabular}{|c|c|c|c|c|c|}
\hline $\begin{array}{c}\text { Openings } \\
\text { [\%] }\end{array}$ & $\begin{array}{c}G_{f} \\
{[N / m]}\end{array}$ & $\begin{array}{c}E \\
{\left[N / \mathrm{mm}^{2}\right]}\end{array}$ & $\begin{array}{c}\quad f_{t} \\
{\left[\mathrm{~N} / \mathrm{mm}^{2}\right]}\end{array}$ & $\begin{array}{c}k_{n} \\
{\left[\mathrm{~N} / \mathrm{mm}^{3}\right]}\end{array}$ & $\begin{array}{c}\text { Interface shear } \\
\text { behavior/Trough } \\
\text { shape } \\
{[-]}\end{array}$ \\
\hline$x_{1, \text { ref }}=30$ & $x_{2, \text { ref }}=10$ & $x_{3, r e f}=3000$ & $x_{4, \text { ref }}=0.10$ & $x_{5, \text { ref }}=0.7 \times 10^{9}$ & $x_{6, \text { ref }}=1$ \\
\hline$x_{1}=31.92 \div 33.88$ & $x_{2}=12$ & $x_{3}=3000$ & $x_{4}=0.10$ & $x_{5}=[$ See Table 5$]$ & $x_{6}=1$ \\
\hline
\end{tabular}

Parameters $x_{1}$ to $x_{4}$ are derived according to the material properties used in the finite element analysis and the geometry of the nave. Parameter $x_{6}$ is assigned its reference value according to [5]. Special attention is drawn to the parameter $x_{5}$ related to the normal stiffness of the soil-structure interface. The reference value for $x_{5}$ has been calculated according to typical Dutch pile foundation systems distributed along the façade of brick masonry structures [19]. In the present research, this parameter is calculated from the modulus of subgrade reaction under vertical loading of the foundation system of the nave, an approach that generalizes the applicability of the damage function to other foundation and soil types. This approach additionally allows for taking into account foundation strengthening, micro-piling and foundation soil improvement directly in the damage function. 
For strip foundations, the modulus of subgrade reaction $k_{n}$ is directly equivalent to the parameter $x_{5}$ and can be applied to continuous shallow foundations of masonry walls. Equations for its calculation are available in the literature (e.g. [20,21]). Some further manipulation is required in the case of colonnades founded on individual footings, as is the case with the nave pillars of the present case study. The $x_{5}$ parameter for a series of $m$ single footings $j$ is then calculated as follows:

$$
k_{n}=\frac{\sum_{j=1}^{m} k_{n}^{j} A_{f}^{j}}{\sum_{j=1}^{m} A_{f}^{j}}=x_{5}
$$

where $k_{n}^{j}$ is the modulus of subgrade reaction of footing $j$. This can be calculated from equations (3) and (4) or from equations (4) and (5) if the settlement has been pre-estimated. This averaging approach to the subgrade reaction modulus is similar to the one followed for the allocation of the stiffness provided by the distributed piles according to Rots [19], but can be generalized as shown for continuous footings of walls or isolated footings of colonnades. This parameter becomes significant in light of the results shown in Figure 12. Despite the decrease of the deflection ratio as the phases progress, the damage, in terms of crack width, increases. This is captured by the damage model through the change in the $x_{5}$ parameter due to soil-structure interaction (decrease of the apparent Young's modulus of the foundation soil within a single phase). The disposition of the data points, capable of being approximated by a third order polynomial fit, suggests that the damage model can be successfully adapted to this case.

In addition to adjusting the reference value for the vertical interface stiffness $\left(x_{5}\right)$, the $a_{5}$ coefficient associated with the interface stiffness is also adapted. These parameters are modified in order to fit the available numerical results of the phased analysis (phase B and C) and the reference model. The material properties of masonry are taken as equal to those of the wall masonry (Table 1), which comprises most of the structure and on which the majority of the damage is accumulated. The percentage of openings varies between $33.88 \%$ in phase B and $31.92 \%$ 510 in phase $\mathrm{C}$ and the reference model. 


\section{$511 \quad 5.2$ Results}

512 Using equation (8) the values for the parameter $x_{5}$ are found for the colonnade. These are shown in Table 5,

513 where it becomes apparent that the range of the parameter values varies within the range initially investigated in

514 [5], with the exception of the reference model case. Nevertheless, it is expected that the calibrated values for the

515 numerical model parameters be significantly different from those initially proposed. This is due to the fact that the

516 initial model was calibrated against a finite element benchmark where the interface stiffness was not extensively

517 investigated. A complete recalibration of the model is bound to alter the numerical parameters to some degree.

518 The slight increase of $x_{5}$ during the transition from long-term phase B to short-term phase $\mathrm{C}$ is contrary to the 519 progress of soil consolidation, which decreases the Young's modulus of the soil. However, depending on the 520 calculation method elected (such as for the estimated settlement method employed here or for continuous footings), 521 the $x_{5}$ parameter may depend directly or indirectly on the stiffness of the superstructure as well. This stiffness is 522 increased by the addition of the second level of the nave wall. This fact clearly illustrates the significance of soil523 structure interaction in the study of differential settlement damage problems.

524 The analytical model, when used with its initial reference values and normalization process, greatly 525 exaggerates the damage corresponding to the reference model and underestimates the damage in the phased 526 analysis (phases B and C). The calibration of the new parameters is performed by a simple minimization process, 527 during which the linear regression between FE and analytical crack widths is required to be a unitary slope curve.

528 The normalization of the $x_{5}$ parameter in [5] is carried out according to:

$$
\overline{x_{5}}=\frac{\log _{10} x_{5}-\log _{10} x_{5, \text { ref }}}{2}
$$




$$
\overline{x_{5}}=\left(\frac{\log _{10} x_{5, r e f}}{\log _{10} x_{5}}\right)^{1.5}
$$

531

532

533

534

535

536

537

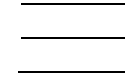

Table $5 \quad x_{5}$ parameter results for phase B model, phase $\mathrm{C}$ model and reference model.

The results of the modified analytical model are compared with the finite element analysis results in terms of the main cracks of the first level of the nave wall, following their calculation as described in the phased analysis section. The minimization process for the available data set produces a value for the $a_{5}$ parameter equal to -1.1722 . The comparison of the results is plotted in Figure 17a, in which satisfactory agreement is found throughout the range of available data. Despite some discrepancy in the results in terms of crack width, the damage level is well approximated by the calibrated model.

The envelope indicating the change in the polynomial model curve, almost entirely due to alterations in the spring stiffness and to a very minor extent due to changes in the opening percentage, is presented in Figure $17 \mathrm{~b}$.

540 The upper envelope curve corresponds to the maximum apparent stiffness associated with the reference model and

541 the lower curve corresponds to the minimum apparent stiffness of the long-term part of phase C. This fact

542 illustrates the influence of the foundation stiffness, and, by extension, the properties of the soil, on the behavior of 543 complex structures. 


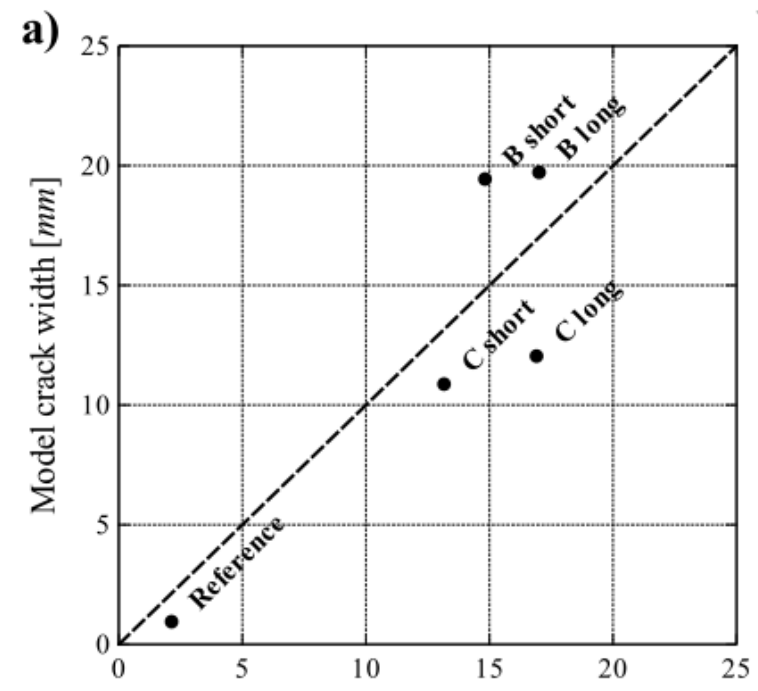

FE crack width $[\mathrm{mm}]$

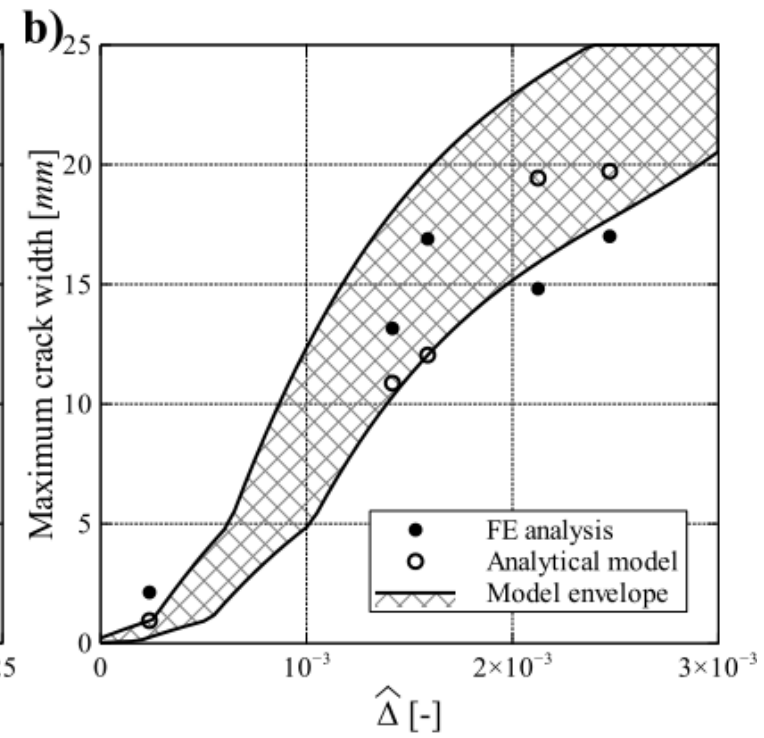

$\widehat{\Delta}[-]$

Figure 17 a) Comparison of analytical model with FE analysis results. Dashed diagonal indicates line of equality between FE analysis and analytical modeling. b) Crack width according to damage prediction model and comparison with $\mathrm{FE}$ analysis results.

The initial results of this approach towards the extension of the predictive analytical model are promising. The generalization of this extension requires robust verification in order to recalculate the numerical coefficients of the model. Coupled experimental tests and parametric numerical analyses need to be developed, along the same lines of the prior development of the analytical model but attempting to include variations in the vertical stiffness of the foundation. This is likely to lead to modifications to all numerical parameters, unlike the simplified calibration approach adopted in this paper, where only the parameters linked with the vertical stiffness were modified.

\section{Conclusions}

In this study the behavior of a church nave wall subjected to ground deformation over an extended period of time is investigated. The problem is approached through single-phase and multi-phase finite element analysis. The paper demonstrates the importance of detailed modeling of the soil behavior over time, the soil-structure interaction and the accurate measurement of settlements for the analysis of complex structures subjected to soil movement. Through this investigation it is shown that the application of a single-phase analysis does not reliably provide the cracking pattern observed in the actual structure. The need to take into account construction phases 
and changes in the soil stiffness is clearly shown, even when studying individual element ensembles, such as the nave wall here investigated. The importance of detailed geometric and damage survey is also demonstrated.

The sensitivity analysis illustrates the predominance of the deformation profile, as influenced mainly by the soil-structure interaction, in the disposition of the cracking pattern on the structure. Nevertheless, the width of the cracks is strongly influenced by the material properties of the nave wall, as are the obtained settlements, although to a lesser degree.

The phased analysis, taking into account changes in the behavior of the soil and alterations in the geometry of the structure, provides a complete picture of the history of the nave's pathology. Different major cracks appear and develop at different phases of the building, due to redistribution of the forces and changes in the stiffness of the foundations.

An analytical model for the prediction of the damage level in masonry structures subjected to differential settlements is adapted and expanded. Moving beyond the initial formulation of the model, a method for the direct calculation of the normal stiffness of the structure is proposed. Following calibration of the numerical coefficients linked to this stiffness, the results of the model are consistent with the numerical analysis results and the crack state of the real structure. Further expansion of the model along the lines pursued here can greatly enhance the potential for accurate analytical modeling of complex masonry structures.

\section{Acknowledgements}

The authors acknowledge the funding received by BRAIN.be, Belspo in support of the GEPATAR research project ("GEotechnical and Patrimonial Archives Toolbox for ARchitectural conservation in Belgium" BR/132/A6/Gepatar).

\section{References}

[1] A.R. Sánchez, R. Meli, M.M. Chávez, Structural Monitoring of the Mexico City Cathedral (1990-2014), Int. J. Archit. Herit. 10 (2016) 254-268. doi:10.1080/15583058.2015.1113332. 
[2] L. Giresini, Energy-based method for identifying vulnerable macro-elements in historic masonry churches, Bull. Earthq. Eng. 14 (2016) 919-942. doi:10.1007/s10518-015-9854-7.

[3] P. Roca, M. Cervera, L. Pelà, R. Clemente, M. Chiumenti, Continuum FE models for the analysis of Mallorca Cathedral, Eng. Struct. 46 (2013) 653-670. doi:10.1016/j.engstruct.2012.08.005.

[4] S. Saloustros, L. Pelà, P. Roca, J. Portal, Numerical analysis of structural damage in the church of the Poblet Monastery, Eng. Fail. Anal. 48 (2015) 41-61. doi:10.1016/j.engfailanal.2014.10.015.

[5] G. Giardina, M. Hendriks, J.G. Rots, Damage Functions for the Vulnerability Assessment of Masonry Buildings Subjected to Tunneling, J. Struct. Eng. 141 (2015) 1-13. doi:10.1061/(ASCE)ST.1943$541 X .0001162$.

[6] L. Schueremans, K. Van Balen, K. Brosens, D. Van Gemert, P. Smars, The Church of Saint-James at Leuven: Structural Assessment and Consolidation Measures, Int. J. Archit. Herit. 1 (2007) 82-107. doi:10.1080/15583050601126137.

[7] S. Sanchez-Beitia, L. Schueremans, K. Van Balen, On-site stress measurement on the piers of the Saint Jacobs church in Leuven, Belgium, Int. J. Archit. Herit. 3 (2009) 110-125. doi:10.1080/15583050802278794.

[8] E. Verstrynge, L. Schueremans, P. Smars, Controlled Intervention: Monitoring the Dismantlement and Reconstruction of the Flying Buttresses of Two Gothic Churches, Int. J. Archit. Herit. 6 (2012) 689-708.

[9] G. Heirman, K. Brosens, Uitvoeringsdossier Globale Stabiliteitswerken Sint-Jacobskerk. Internal report D/0800/10, Triconsult nv, 2017.

[10] M. Bassier, G. Hardy, L.-E. Bejarano-Urrego, A. Drougkas, E. Verstrynge, K. Van Balen, M. Vergauwen, Semi-automated creation of accurate FEM meshes of heritage masonry walls from point cloud data, in: 11th Int. Conf. Struct. Anal. Hist. Constr. Cusco, Peru, 2019: pp. 305-314. 
606

607

608

609

610

611

612

613

614

615

616

617

618

619

620

621

622

623

624

625

626

[11] K. Van Balen, K. Nuyts, P. Smars, D. Van de Vijver, Optimalisatie van standzekerheidsmodellen van gewelfde gotische structuren gebruik makend van informatie uit vervormingsmetingen en scheuranalyse. Internal report PV30318, KU Leuven, 1995.

[12] A.W. Koppejan, A formula combining the Terzaghi load compression relationship and the Buisman secular time effect, in: Proc. 2nd Int. Conf. Soil Mech. Found. Eng., 1948: pp. 32-38.

[13] G. Giardina, A. V van de Graaf, M. Hendriks, J.G. Rots, A. Marini, Numerical analysis of a masonry façade subject to tunnelling-induced settlements, Eng. Struct. $54 \quad$ (2013) 234-247. doi:10.1016/j.engstruct.2013.03.055.

[14] A. Drougkas, P. Roca, C. Molins, Numerical prediction of the behavior, strength and elasticity of masonry in compression, Eng. Struct. 90 (2015) 15-28. doi:10.1016/j.engstruct.2015.02.011.

[15] H.W. Reinhardt, Fracture Mechanics of an Elastic Softening Material Like Concrete., Heron. 29 (1984) 142. doi:10.1023/A:1012235530463.

[16] G. Gazetas, Foundation Vibrations, in: H.-Y. Fang (Ed.), Found. Eng. Handb., 1991: pp. $553-593$. doi:10.1007/978-1-4615-3928-5_15.

[17] TNO, DIANA Finite Element Analysis, User's Manual, (2017).

[18] J.B. Burland, C.P. Wroth, Settlement of buildings and associated damage, in: Settl. Struct. Proc. Conf. Br. Geotech. Soc., 1974: pp. 611-764.

[19] J.G. Rots, Settlement Damage Predictions For Masonry, in: Maint. Restrengthening Mater. Struct. Brick Brickwork Proc. Int. Work. Urban Herit. Build. Maint. IV, 2000: pp. 47-62.

[20] M.A. Biot, Bending of an infinite beam on an elastic foundation, J. Appl. Math. Mech. 2 (1937) $165-184$. doi:10.1016/0021-8928(58)90136-9. 
627 [21] A.B. Vesić, Beams on Elastic Subgrade and the Winkler's Hypothesis, in: Proc. 5th Int. Conf. Soil Mech. Found. Eng. Paris, Fr., 1961: pp. 845-850. 